\title{
O Serviço Social e o Desenvolvimento Local - Tratamento a Dependentes Químicos: Um Relato de Experiência
}

\author{
Social Service in the Treatment of Substances Attached Psychoactive: An Experience \\ Report
}

\author{
El Servicio Social y el Desarrollo Local - Tratamiento a Dependientes Químicos: Un \\ Relato de Experiencia \\ Celisa Aparecida Silva de Barros \\ Heitor Romero Marques \\ Universidade Católica Dom Bosco (UCDB)
}

\begin{abstract}
Resumo
O presente trabalho aborda de forma objetiva um relato de experiência vivido através da implantação do serviço social na Comunidade Terapêutica Antônio Pio da Silva "Centro de Tratamento de Dependência Química Álcool e Drogas". O estudo descreve a atuação do profissional de serviço social, visando à efetivação do protagonismo do usuário de substâncias psicoativas e destaca que a dependência química é uma doença biopsicossocial e não acarreta danos somente ao adicto e sim a toda à rede familiar e social o qual este pertence. $\mathrm{O}$ estudo de caso ora relatado permitiu reconhecer a eficácia do tratamento, com a efetiva participação do profissional do serviço social. Palavras chave: Dependência química. Serviço social. Comunidade terapêutica.
\end{abstract}

\begin{abstract}
The present paper an objective account of a lived experience through the implementation of social service in the Therapeutic Community Antonio Pio da Silva "Center for Treatment of Alcohol and Drug Addiction." The study describes the work of professional social work, aiming at the effectuation of protagonism of psychoactive substances users and highlight that drug addiction is a biopsychosocial disease not only causes damage to the addict only but the entire family and social network to which this belongs to. The case study reported here allowed us to recognize the effectiveness of treatment, with the active participation of professional social work.

Keywords: Addictio., social service. Community Therapy.
\end{abstract}

\section{Resumen}

El presente trabajo presenta de manera objetiva um relato de experiência vivido a traves de la implantación del servicio social en la Comunidad Terapêutica Antonio Pio da Silva "Centro de Tratamento de Dependência Química Álcool e Drogas. El estudio describe la atuación del profisional del servicio social, con el objetivo a la efetivación del protagonismo del usuario de substancias psicoativas y destaca que la dependencia química es una enfermidad biopsicosocial y no acarreta prejuicios solamente al adicto todavía a toda a la red familiar y social al que pertenence. El estudio de caso relatado permitió reconocer la eficacia del tratamiento, con la efectiva participación del profisional del servicio social.

Palavras clave: Dependencia química. Servicio social. Comunidad terapeutica.

\section{Introdução}

O ser humano está sempre em busca da felicidade, alegria, satisfação, independente de onde esteja. O problema é que em busca desse bem estar, em seu cotidiano, sem perceber, acaba direcionando seus problemas para outros aspectos da vida, a exemplo da dependência de substâncias psicoativas.

O presente estudo deu-se por meio de pesquisaação desenvolvida no Programa de pós graduação stricto sensu em Desenvolvimento Local em Contexto de Territorialidades da Universidade Católica Dom Bosco, no decorrer do ano de 2010.

A experiência aqui relatada deu-se no contexto de um trabalho desenvolvido pelo Serviço Social da Comunidade Terapêtica Antônio Pio da Silva (COMTAPS), "Centro de Tratamento de Dependência
Química Álcool e Droga" em Campo Grande, Mato Grosso do Sul, onde é oferecido tratamento do álcool e das drogas para 25 internos do sexo masculino com idade mínima de 18 anos.

A instituição acima indicada auxilia no tratamento a toxicômanos e etilistas desde abril de 2007, cuja atuação se dá em uma visão ecumênica, que trabalha com o modelo Minessota - 12 passos de Narcóticos Anônimos (NA), que visa recuperar e resgatar o ser humano num todo, buscando a sua reinserção e reabilitação social, com uma melhor qualidade de vida. Tem como meta o resgate da autoestima, incentivando de modo permanente a autodisciplina nos internos. Na consecução de seus objetivos oferece atividades de laborterapia; atendimento individual; dinâmicas em grupos; palestras socioeducativas e curso profissionalizante, ou seja, procura promover a reabilitação de pessoas dependentes químicas vendo-a 
como um todo.

$\mathrm{O}$ atendimento é desenvolvido por uma equipe multiprofissional, respeitando-se a formação religiosa de seus residentes, mas sempre buscando o fortalecimento dos vínculos familiares e na sociedade.

A pesquisa estabeleceu como objetivo demonstrar que a dimensão humana do dependente químico deve ser levada em consideração, notadamente quanto à necessidade se torná-lo um agente de sua própria recuperação. O desenvolvimento local tem como pressuposto a idéia de que uma comunidade, mesmo que terapêutica, pode ser mobilizada em vista da superação de suas necessidades. A profissionalização é outro pressuposto indispensável para a compreensão do que é o Desenvolvimento Local. Então, as atividades desenvolvidas na pesquisa-ação vieram ao encontro de tal premissa e possibilitaram avanços significativos em termos de qualidade de vida.

\section{Alguns entendimentos da drogadição}

O alcoolista ou usuário de drogas na maioria das vezes, em uma visão empírica, é associado a mendigo, vagabundo, àquele que fica perambulando pelas ruas e representando risco à sociedade. Atualmente a dependência pode estar escondida em bolso de paletós de executivos bem sucedidos, de donas de casa com problemas familiares, do aluno que sai da escola e vai beber com colegas, do aposentado com o costume de se reunir com os amigos em bares, ou seja, nenhuma pessoa pode afirmar que não está sujeita a ser dependente de alguma substância psicoativa, seja qual for sua condição social. A idade é outro fator que não exime ninguém do contato com o álcool ou outra droga e até mesmo de se tornar dependente da mesma, pois todos nascem com alguma predisposição e ao longo da vida, pode ter contato com essas substâncias e assim ter a doença instalada.

Ninguém nasce dependente do álcool e muito menos se torna dependente de uma noite para o dia, embora existam tipos de drogas que causam dependência já nas primeiras vezes de uso. Ressaltase que o uso de substâncias ocorre após a pessoa haver experimentado, às vezes por simples curiosidade. O padrão de consumo dos vários tipos de droga vai modificando e a intensidade, concentrações e quantidades, aumentando, encaminhando-se para o uso sempre prejudicial (PEREIRA; PILLON. 2004 p.97).

A Organização Mundial da Saúde (OMS) define droga como sendo qualquer substância que introduzida no organismo vivo, possa modificar uma ou mais de suas funções, quando esta entra na corrente sanguínea atinge o cérebro e altera seu equilíbrio.

O Ministério da Saúde do Brasil reconhece o alcoolismo como um problema de saúde pública, portanto, é necessário o empenho de toda a sociedade para que estes dependentes sejam assistidos pelos serviços públicos oferecidos e estimulados ao resgate de sua autonomia e dignidade no convívio familiar e comunitário.

A dignidade humana precisa ser construída em bases comunitárias sólidas de amizade, comunhão, superação de dificuldades, fortalecimentos da homoestase e dos laços familiares, sem o que a pessoa perde a referência social e psciológica (MARQUES, 2009).

O álcool é uma substância depressora do Sistema Nervoso Central que afeta as regiões do cérebro responsáveis pela censura interna e o autocontrole (DOMINGOS 2008).

Cabe ressaltar que o álcool é tido como uma droga lícita que acarreta danos psíquicos e físicos no que tange às doenças cardiovasculares, cirrose hepática, câncer na boca e esôfago, dentre outras. Importante enfatizar que de acordo com o levantamento domiciliar sobre o uso de drogas no Brasil, realizado pelo Centro Brasileiro de Informações sobre Drogas Psicotrópicas (CEBRID) em um estudo envolvendo as 107 maiores cidades do Brasil em 2001, 11,2\% da população brasileira são dependentes de álcool, esta é a principal dependência no Brasil, comprovando assim, ser a terceira moléstia que mais mata no mundo.

\section{A atuação do serviço social no tratamento a dependentes de substâncias psicoativas}

$\mathrm{Na}$ área social o atendimento aos dependentes de substâncias psicoativas visa o resgate do ser humano, por meio da promoção da cidadania, da autoestima e principalmente pela reestruturação e fortalecimento dos vínculos familiares. Portanto, o serviço social da Comunidade Terapêutica Antônio Pio da Silva se caracteriza pelo atendimento técnico, estudo de caso, trabalho com a família, ações voltadas para a qualidade de vida, palestras sócio-educativas, e encaminhamentos para a rede socioassistencial. A dinâmica do atendimento aos dependentes corrobora e promove o desenvolvimento local, no viés comunitário. O desenvolvimento comunitário e uma forma de desenvolvimento local centrado nos processos sociais relacionados com a sociologia, a educação e a dinâmica de grupos (GONZÁLES, 1998 apud MARQUES, 2009).

Atuar a escala comunitária corresponde com querer melhorar o aspecto organizativo dos coletivos sociais com o fim de melhorar a qualidade de vida. $\mathrm{O}$ desenvolvimento local a escala humana destaca que as ações dos agentes devem convergir para a promoção do emprego, assistência social e familiar às pessoas mais necessitadas (MARQUES, 2009).

Em setembro de 2009 foi implantado o trabalho de um técnico de serviço social na instituição que se tornou parte da equipe multiprofissional. O referido profissional de Serviço Social, bem como seus acadêmicos estagiários que participaram do planejamento das ações a serem desenvolvidas na comunidade, adquiriu gradativamente conhecimento 
muito específico sobre o tema e se sensibilizou quanto a importância em obter mais fundamentação teórica sobre a drogadição.

Pensar em comunidade supõe a potenciação do associacionismo, fomento dos laços de vizinhança, realce da cultura e do entorno, busca de incremento da comunicação entre os indivíduos, diminuição dos desequilíbrios e desigualdades, fomento de atitudes abertas, dialogantes, ativas, de relação, de trabalho em equipe, melhora do acesso dos mais desfavorecidos aos serviços de informação pública, utilização de programas de fomento e melhora do aspecto econômico, cultural e meio ambiente, utilização de equipamentos socioculturais e projetos coletivos (GONZÁLES, 1998 apud MARQUES, 2009).

$\mathrm{O}$ estudo de caso é uma ferramenta muito rica em relação ao atendimento a usuários de substâncias psicoativas. Por meio dele o profissional realiza um diagnóstico individual, no que é incluída toda a sua história pessoal e social. Busca-se no estudo de caso conhecer os motivos que levaram o usuário a iniciar-se no uso de substâncias, há quanto tempo fez uso, as relações com a família, suas perdas, frustrações, informações que pautarão os encaminhamentos na intervenção do serviço social para cada indivíduo, considerando suas dificuldades e potencialidades.

O trabalho com a família é fundamental para o tratamento do residente e principalmente para seus familiares que se tornaram co-dependentes. Os danos causados às famílias de dependentes químicos são imensuráveis e se caracterizam pelos vínculos afetivos desgastados e rompidos, danos morais, sociais, econômicos e principalmente psicológicos e emocionais.

De acordo com Alvarenga e Luís (2004) no tratamento do etilista a co-responsabilidade dos membros familiares no início do tratamento é de crucial importância, estabelecendo um apoio ao mesmo, principalmente nas primeiras abordagens, quando ainda não se criaram afinidades entre o profissional e o usuário, bem como o comprometimento com os retornos estabelecidos.

O profissional de serviço social além de trabalhar o resgate dos vínculos com as famílias, sempre orienta aquelas que não conhecem os grupos de apoios de auto-ajuda a familiares de dependentes de substâncias psicoativas, pois estes grupos ajudam a entender melhor a dependência como uma doença e a compartilhar com outras pessoas que passam ou passaram por situações iguais ou parecidas em relação às drogas.

Segundo Alvarenga e Luís (2004) no grupo, as famílias podem recontar e recriar suas histórias o que consequentemente modificaram as relações entre seus membros, favorecendo também o processo de tratamento do alcoolista.

As palestras socioeducativas têm por finalidade o resgate de hábitos e limites perdidos, importantes para preservar e manter o bom convívio em coletividade. Reconhece-se que não é fácil conviver com pessoas "desconhecidas" de uma hora para outra, - no caso do tratamento em uma comunidade terapêuticapassar meses com essas pessoas e mesmo estando com elas diariamente, saber respeitar os momentos de privacidades e lidar com as diferenças individuais.

As palestras proferidas na instituição em questão levam em conta o fato de que muitos internos já foram moradores de rua. Entende-se também que muitos usuários não se importavam em ser sociáveis a outras pessoas e muito menos "tolerá-las".

O trabalho em rede na COMTAPS é um aspecto que o Serviço Social está sempre enfatizando e fortalecendo, principalmente com as demais políticas públicas. A COMTAPS se articula com o Programa Mesa Brasil, CAPS AD, Policlínica da Prefeitura de Campo Grande (serviço odontológico em endodontia e restauração), ONG FIL (serviço odontológico básico), Hospital Regional e CAPS AD (psiquiatra), Cem (exames DST/AIDS), Instituto de Identificação (segunda via de identidade), UNIDERP (aula de matemática e nutrição), instituição Federação Inclui Brasil (palestra de motivação e reinserção à sociedade) e com a Secretaria de Estado de Educação quando o COMTAPS necessita de doações de materiais escolares, parcerias estas firmadas após a implementação do Serviço Social.

A atuação e atribuições do profissional de Serviço Social em uma comunidade terapêutica por ser caracterizada como uma ONG integrante do terceiro setor necessita ser pró-ativa, elaborando projetos para captação de recursos, viabilização de convênios, busca por doações, voluntariado, serviços gratuitos pertinentes às necessidades da instituição. As ações voltadas para a qualidade de vida visam resgatar a cidadania, dignidade e hábitos sociais saudáveis. $\mathrm{O}$ lazer contribui de modo significativo para o alcance de tal objetivo.

De acordo com a abordagem de Prochaska e Di Clemente a motivação para o tratamento e a mudança de comportamento em relação ao uso de drogas seria permeável às influências ambientais e pessoais (LUÍS, TAVEIRA, 2004, p. 264).

$\mathrm{O}$ incentivo aos jogos esportivos em momentos de lazer dos internos é importante, pois impulsiona o trabalho em equipe, a paciência com o próximo, a aceitação e a compreensão diante de uma derrota, trabalhando as relações interpessoais.

O profissional com percepção consegue captar muitos sentimentos e expressões passadas pelos internos, sem que eles se dêem conta que estão sendo observados e estudados. O simples fato de dividir um prêmio voluntariamente com o colega recém-chegado já demonstra o apoio e a união que eles reafirmam neste processo de tratamento conjunto.

$\mathrm{O}$ enfoque no resgate de festas saudáveis 
foi perdido e esquecido por muitos internos da COMTAPS cujo resgate faz parte das atividades terapêuticas. Em datas comemorativas, é importante que os profissionais observem os internos que no meio da festa se afastam ou ficam cabisbaixos. Eles se deprimem muitas vezes pelo fato de em momentos como esses junto à família não terem dado o devido valor ou não o terem vivenciado. Cada um reage de uma maneira, há internos que ficam emocionados. Essas reações não devem ser vistas como um fato isolado. Ao contrário, tais reações diferenciadas são importantes para uma possível intervenção grupal, pelo fato de não se tratar apenas de um interno, mas de um grupo de pessoas que necessitam de terapia.

Em datas mais comemorativas como o Natal e o Ano Novo, há o despertar de uma ansiedade muito grande nos internos, pelo fato de que anteriormente essas datas eram, via de regra, celebradas com bebidas alcoólicas e muitos deles também faziam uso de outras substâncias. O carnaval é outra data que eles ficam muito inquietos, com vontade de sair, pensam que estão perdendo um grande acontecimento. Apenas esses episódios permitem afirmar que é muito complexo lidar com dependentes de substâncias químicas, mas mesmo em momentos de lazer os profissionais devem estar atentos a essas questões.

As dinâmicas em grupo têm o objetivo de deixar os internos mais à vontade para colocarem seus pontos de vistas diante de determinadas situações que via de regra eles têm receio em dizer. Ao expor sentimentos relacionados com o grupo, é impressionante como estas atividades ajudam no relacionamento tanto entre os internos quanto com os demais profissionais. Diante de tudo isso o profissional pode abordar assuntos mais complexos que precisam ser esclarecidos ou enfatizados no tratamento dos usuários, que ocorre de forma mais descontraída com um alto nível de aceitação e alcance dos objetivos da mensagem a eles transmitida.

\section{0 diagnóstico social e o estudo de caso}

Cada ser humano é único em sua vivência e em seu modo de se relacionar com o outro, suas reações distintas nas mais variadas situações. A vida de cada pessoa, independente das semelhanças com o próximo, tem suas particularidades. As ações desenvolvidas pelo serviço social na Comunidade Terapêutica Antonio Pio da Silva: Centro de Tratamento de Dependência Química Álcool e Droga (COMTAPS) sempre se embasam no conhecimento pessoal de cada interno e nas manifestações que surgem em grupo.

$\mathrm{O}$ primeiro contato do assistente social com o interno se dá por meio da triagem do Serviço Social, que se vale de uma ficha social usada como um dos instrumentos do estudo de caso. A ficha social elenca os dados sócio-econômicos, incluindo a renda de cada integrante da família, assim como o grau de escolaridade, benefícios, idade, problemas de saúde, dentre outros.

De acordo com o Dicionário de Termos Técnicos da Assistência Social o estudo de caso é:

Atividade técnica utilizada durante o processo de acompanhamento, para elaboração de diagnóstico sobre determinado indivíduo, família e grupo, visando à realização de intervenções. Inclui coleta de dados sobre a história pessoal e social, sistematização das informações e produção de conhecimento (BH, 2007, p.42).

O conhecimento passado pelos internos quando da triagem é imensurável, ocorrem muitas situações em que o usuário relata fatos da vida privada, que eles nunca conversaram a respeito com outras pessoas. Nesse processo enfatiza-se a ética profissional, o sigilo das informações, e principalmente a sinceridade, porque por meio dessa abordagem buscam-se as intervenções necessárias para o caso em particular e para tanto a confiança necessita ser estabelecida.

No momento do histórico social, aborda-se com mais ênfase o inicio da drogadição do interno, as situações que o levaram ao uso e o rumo que sua vida tomou desde então. Ressalta-se que é comum o interno, em dados momentos, ir em direção a um atendimento psicológico. Nessas circunstâncias é importante que certas informações sejam repassadas para o profissional de psicologia, devido ao fato de que atuação técnica do assistente social não ser pertinente a algumas temáticas.

As informações sobre a família são essenciais, não apenas do ponto de vista socioeconômicos, mas a relação estabelecida entre esta e o interno. Um exemplo a ser colocado é o de W. Em sua residência mora sua esposa de 40 anos, seu filho de 21 anos, duas filhas: uma de 14 anos e a outra com 18 anos, um sobrinho de 25 anos, deficiente intelectual e o cunhado de 45 anos. O grau de escolaridade de todos os filhos se encontra no mesmo patamar: a sétima série do ensino fundamental, somente a filha de 14 anos continua estudando. O cunhado é o único que possui renda fixa em torno de seiscentos reais, a filha de 18 anos está à procura de emprego, a esposa não pode trabalhar devido a problemas psiquiátricos advindos de distúrbios emocionais acarretados pelo uso de droga do marido, que é interno na instituição. $\mathrm{O}$ mesmo não recebe nenhum benefício pelo fato de seu último emprego ter sido como trabalhador autônomo. Este passou os últimos doze dias morando na rua, ficou sabendo do tratamento desenvolvido pela comunidade terapêutica e procurou o Serviço Social da instituição que posteriormente entrou em contato com sua família, informando sua situação e a opção de iniciar o tratamento.

Percebe-se no caso apresentado que a família se torna doente diante de um membro da mesma estar dependente de drogas. Neste caso a droga de uso é a pasta base. Esta família visivelmente se encontra em estado de extremada vulnerabilidade social. 
O profissional de serviço social neste caso realiza uma visita familiar, iniciando um novo processo de encaminhamentos e intervenções. O acompanhamento do usuário é mantido em todo o seu tratamento.

O diagnóstico social permite uma visão mais global dos internos da COMTAPS, no aspecto de características do grupo, suas dificuldades e potencialidades. Percebe-se através de suas fichas sociais a necessidade de acompanhamentos, dinâmicas e diálogos em grupo. Tais atividades em grupo propicia uma visão das ações a serem desenvolvidas voltadas às semelhanças emergentes entre eles.

De acordo com o Dicionário de Termos Técnicos da Assistência Social o diagnóstico social é:

Instrumento dinâmico que permite uma compreensão da realidade social, incluindo a identificação das necessidades e a detecção dos problemas prioritários e respectivas causalidades, bem como dos recursos e potencialidades locais, que constituem reais oportunidades de desenvolvimento (BH, 2007, p.35).

Em junho de 2010 foi realizada a última etapa da pesquisa a fim de atualizar o diagnóstico social da instituição, devido à mudança da demanda de usuários desde o último diagnóstico realizado e para tanto levou-se em conta o fato de que alguns internos não concluem o tratamento bem como a entrada de outros. Esse diagnóstico social é sempre embasado nas fichas sociais dos internos e nos acompanhamentos dos mesmos, totalizando dezoito internos.

Os resultados obtidos por meio do diagnóstico social mostram o quanto a influência é um fator determinante no uso de drogas visto que $80 \%$ dos internos iniciaram o uso de drogas por influência de amigos.

$\mathrm{O}$ mesmo diagnóstico social indica que cerca de $65 \%$ já passaram por mais de dois tratamentos e muitos alegam dificuldades de conviver em grupo e não terem se conscientizado anteriormente que precisavam se tratar. A maioria não conclui o tratamento por pensarem que não precisam terminar o mesmo para não voltar a usar drogas. Aspecto importante a ser mencionado é o fato de todos os internos da COMTAPS ainda manterem vínculos com sua família. Eles ainda declaram a importância da família em seu tratamento e são conscientes do sofrimento que dispensaram às mesmas devido ao uso de drogas.

No aspecto familiar o diagnóstico social permitiu constatar que $47 \%$ dos internos são casados, embora nem todos os casados tenham filhos. Ainda assim $50 \%$ são pais, entre solteiros e casados. Em relação aos pais que têm filhos de relacionamentos terminados, percebe-se a dificuldade em alguns casos em manterem o contato com seus filhos, cujo aspecto é sempre abordado no acompanhamento, para que não seja perdido o vínculo entre pai e filho. Algumas das justificativas é o fato da perda da confiança e da melhor situação tanto financeira tanto emocional do padrasto. Importante registrar que todos os residentes possuem religião.

O uso de substâncias psicoativas levam as pessoas aos extremos a fim de manter o vício, muitos dependentes optam pelo crime para manter seu uso. No diagnóstico social constatou-se que $50 \%$ dos internos já responderam processos judiciais e $47 \%$ estiveram detidos, considerando que $100 \%$ já praticaram pequenos furtos em residências particulares. $\mathrm{Na}$ instituição $25 \%$ dos usuários chegaram a morar na rua em condições subumanas, muitos destes compartilham os momentos em que estavam na rua na chuva, com vontade de voltar para casa, de parar de usar drogas, mas mesmo chorando faziam o uso das drogas, que já não eram mais tão prazerosas. Um dado alarmante é o fato de que $70 \%$ dos internos serem poliusuários, ou seja, usam mais de uma substância psicoativa.

A necessidade básica de segurança, proteção e alimentação, há muito defendida por Abram Maslow é algo amplamente defendido por aqueles que pretendem o desenvolvimento local a partir da plena condição humana (MARQUES, 2009).

\section{0 trabalho multidisciplinar}

A atuação do assistente social no tratamento a dependentes de substâncias psicoativas está inserida no trabalho multidisciplinar e interdisciplinar. $\mathrm{Na}$ COMTAPS este é realizado por três coordenadores da instituição, uma assistente social, duas psicólogas, uma enfermeira e quatro estagiários em serviço social, cuja dinâmica de trabalho em equipe permite conhecer melhor cada usuário sob diferentes aspectos. O trabalho desenvolvido por um integrante da equipe, em sua especificidade de abordagem, é compartilhado com os demais, resultando em efetivo atendimento integral do interno da instituição.

Pode-se considerar equipe um grupo que compreende seus objetivos e está engajado em alcançá-los, de forma compartilhada. A comunicação entre os membros é verdadeira, opiniões divergentes são estimuladas. A confiança é grande, assumem-se riscos. As habilidades complementares dos membros possibilitam alcançar resultados, os objetivos compartilhados determinam seus propósito e direção (MOSCOVICI, 1995, p.05).

O trabalho psicossocial é de extrema importância no tratamento a dependentes de substâncias psicoativas e se dá por meio da atuação do Serviço Social em consonância com a Psicologia. Não há como os problemas sociais não influenciarem nos psicológicos e vice-versa. A parceria com o Setor de Enfermagem nos temas voltados à saúde em que são abordados no acompanhamento do Serviço Social é muito rica. Ocorre que muitos internos declaram nas entrevistas as situações de risco que passaram no decorrer de sua drogadição ativa. Neste aspecto o usuário aceita um encaminhamento para a Enfermagem. Para tanto, 
se articula com o profissional de Enfermagem as possíveis formas de conscientização dos internos, seja por meio de palestras, dinâmicas, dentre outras, competindo ao profissional de Serviço Social prestar as devidas informações para o enfermeiro, para que esse possa intervir.

É importante ressaltar o companheirismo com os coordenadores da instituição. Pelo fato de já terem sido usuários de substâncias psicoativas e se encontrarem abstêmios, possuem um conhecimento que nenhum livro pode passar com tanta propriedade e riqueza de detalhes. Ocorrem situações que buscando compreendê-las em bases teóricas ainda assim fica difícil entendê-las em relação aos internos, mas com a contribuição destes coordenadores tudo se torna mais fácil, inclusive apontando as causas da rejeição em certas ações a serem desenvolvidas pelo usuário. Mesmo estes coordenadores não tendo uma formação em nível superior o conhecimento sobre o que se passa na mente dos usuários em recuperação, vai além do que qualquer outro profissional possui.

A metodologia usada pela instituição no tratamento é a Minesota, composta por 12 passos, distribuídos em 64 tarefas. O trabalho do Serviço Social na comunidade terapêutica deve estar em consonância com os objetivos da metodologia, conhecê-la é fundamental para que não haja um desrespeito ao trabalho aplicado pelos demais profissionais, como seguem:

Primeiro Passo: admite-se que se era impotente perante adicção, e que a vida tinha se tornado incontrolável. $\mathrm{O}$ estudo do Primeiro Passo compreende as 16 primeiras tarefas, que se inicia com uma retrospectiva da semana anterior à vinda para a comunidade, para que se tenha uma visão da atual condição. Depois é feito um histórico de vida e um esclarecimento sobre o surgimento e os efeitos dos tóxicos ou álcool. Faz-se também um relato com os fatos que o fizeram vir para a comunidade. Dirá também o porquê precisa e porquê quer este tratamento. Nas tarefas de 08 a 14 são feitos resgates da vida passada, relatando situações de culpa, vergonha, humilhação, desonestidade, orgulho, agressividade, prostituição e irresponsabilidade ocasionadas pelo uso de tóxicos ou álcool.

Segundo Passo: deve-se acreditar que um Poder Maior do que todos pode devolver a sanidade.O estudo deste passo compreende as tarefas de numero 17 a 27 . São identificadas as parcelas de responsabilidade do residente na sua história de mágoas, perdas, conflitos e abandonos. Fará uma lista de raivas e ressentimentos. Relatará também situações em que era importante que não usasse drogas e usou, situações de intolerância e situações de comportamento doentio. Indicará onde em seu corpo foi prejudicado. Fará uma lista de tudo o que perdeu, deixou de ganhar, fazer ou construir pelo seu uso de tóxicos ou álcool.

Terceiro Passo: decide-se entregar a vontade e a vida aos cuidados de Deus, da maneira como O compreendia. Neste passo são relatadas situações em que se tentou controlar pessoas, situações e coisas. Também situações nas quais se tentou controlar e se ficou com raiva por não conseguir. Fazem-se também desenhos dos familiares, identificando seus aspectos positivos e negativos, bem como a qualidade do seu relacionamento.

Quarto Passo: faz-se um profundo e destemido inventário moral de si mesmo. Escrevem-se cartas separadas aos familiares colocando o que gostariam de ter dito a eles e não se teve oportunidade ou coragem, bem como cartas-resposta colocando tudo o que acha que eles lhe responderiam e o que gostaria que respondessem. Faz-se também o exercício do espelho com o intuito de elevar a auto-estima. Faz-se também uma lista dos medos atuais, então se relata os comportamentos e situações que não se quis trazer a público e as apresenta ao conselheiro.Por fim faz seu inventário pessoal e moral.

Quinto Passo: admite-se a Deus, a si mesmo e ao outro ser humano a natureza exata das falhas pessoais. Ë partilhado então o inventário com um membro da equipe, por ele escolhido. Faz em fim uma lista de metas que irá cumprir a sua $10^{\circ}$ Ressocialização: Saídas na 2. ${ }^{a}$ feira com o retorno $6 .^{a}$ feira. Ao retornar da ressocialização fará um relato de quais metas foram cumpridas, como foi o comportamento e quais foram os sentimentos.

Sexto Passo: prontifica-se inteiramente a deixar que Deus remova todos os defeitos de caráter.

Sétimo Passo : humildemente pede-se a Ele que remova todos os defeitos. Faz-se uma lista de todos os defeitos de caráter, que acredita terem trazido problemas.

Oitavo Passo: faz-se uma lista de todas as pessoas que se tenha prejudicado e dispõe-se a fazer reparações a todas elas.

Nono Passo: fazem-se reparações diretas a tais pessoas, sempre que possível, exceto quando fazê-lo possa prejudicá-lo ou a outrem. Faz-se uma lista das pessoas que prejudicou, dizendo os danos causados e de que maneira serão feitas as reparações. Faz-se também um exercício de reparação com 05 cartas. São feitas então as metas para a Segunda ressocialização que é igual à primeira ressocialização.

Décimo Passo: continua-se fazendo um inventário pessoal e quando se estava errado se admite prontamente.Este passo é praticado durante o tratamento inteiro através da folha de sentimentos diários.

Décimo PrimeiorPasso: procura-se, por meio de prece e meditação, melhorar o contato consciente com Deus, da maneira como O compreende, rogando apenas o conhecimento da Sua vontade em relação a si, e o poder de realizar esta vontade.Fazem-se contatos diários e conscientes com o seu Poder Superior.

Décimo Segundo Passo: tendo experimentado o 
despertar espiritual, como resultado desses passos, procura-se levar a mensagem a outros adictos e praticar esses princípios em todas as atividades. Pratica-se o Décimo Segundo Passo levando a mensagem e ajuda aos novos residentes. Faz-se uma retrospectiva de todo o tratamento, relatando dificuldades que encontrou e como ocorreram as mudanças no comportamento e compreensão da própria vida. Enfim, faz-se um plano de vida realista, para os próximos seis meses nas áreas de: recuperação, espiritual, familiar, moradia, educacional, cultural, profissional, esporte, lazer e sexual.

\section{Desenvolvimento local na comunidade}

Ao se estudaro presente temaé fundamental abordar a questão do espaço geográfico da comunidade em questão, enquanto espaço um conjunto indissociável de sistema de objeto e sistema de ações Para tanto, é importante destacar dois planos: o global e o local. O primeiro fala da forma, constituída pelas normas de uso dos sistemas localizados de objetos, enquanto no segundo, o território, organiza uma norma para o exercício das ações. Diante destas duas ordens, se forma uma razão global e uma razão local, que em cada lugar se superpõem e num processo dialético tanto se contrariam quanto se associam. Diante disso, sua definição varia conforme o espaço, ou seja, com a natureza dos objetos e natureza das ações presentes em cada momento histórico.

Percebe-se que não há um tempo global único e nem há um espaço global, apenas espaços da globalização, espaços mundializados reunidos por redes (RIST, 1996 apud MILANI, 2005). O desenvolvimento deve ser entendido levando-se em conta os aspectos locais que têm significado em um território específico. $\mathrm{O}$ global passa a ter sua importância associada ao local e vice e versa, já que um está em constante mudança devido às interferências do outro e, por conta disto, muitos autores utilizam o termo global, como a junção dos dois aspectos, para se referir ao desenvolvimento. Para atuar em uma comunidade é fundamental definir o espaço e o território. O espaço antecede o território e o território se forma a partir do espaço e há ações e ao apropriar-se de um espaço abstrato ou concreto o espaço se territorializa, ou seja, o espaço é a "prisão original" (matéria prima), e o território é prisão que os homens constroem para si (LE BOURLEGAT, 2000).

Ao se destacar esses dois diferencias: espaço e território pode-se caracterizar e tentar interpretar a Comunidade Terapêutica. Para tanto se destaca uma nova concepção de desenvolvimento, que valoriza o local como referência territorial (sentido de lugar) e que ganha força, na Europa, a partir dos anos 1980. Defende-se nessa concepção maior aproximação das pessoas, com apoio na solidariedade comunitária, buscando instrumentalizar a comunidade, envolvendo-a efetivamente na superação dos problemas e na promoção do desenvolvimento endógeno (GOBIERNO BASCO, 1994).

Quando se fala de local, está-se referindo à escala das inter-relações pessoais da vida cotidiana, que sobre uma base territorial constrói sua identidade. O lugar é essa base territorial, o cenário de representações e de práticas humanas que são o cerne de sua singularidade; o "espaço da convivência humana", onde se localizam os desafios e as potencialidades do desenvolvimento (MARTÍN, 1999).

O lugar é o cenário interativo dos acontecimentos, onde os fenômenos naturais e humanos acontecem e produzem seus efeitos. Por isso não é apenas porção e sim síntese da totalidade socioespacial. Há, pois, uma "ordem local" diretamente associada ao cotidiano das pessoas, cujos parâmetros são a copresença, a vizinhança, a intimidade e a cooperação (SANTOS, 1996a). A força do lugar (ordem local) reside no território compartilhado e identificado por uma consciência social e comunitária de entorno, cuja essência é a própria história vivida em comum (SANTOS, 1996a; LÊ BOURLEGAT, 2000).

O lugar se apresenta para as pessoas por sua materialidade, pela aparência conhecida e familiar dos elementos que o compõem - casas, ruas, campos, a vizinhança, o clima habitual, etc.

[...] o agente de desenvolvimento local de fato age, [...] trabalhando e influenciando para que a comunidade mesma desabroche capacidades, competências e habilidades de desenvolvimento, sem a imediatista pretensão de querer levar o desenvolvimento para a comunidade ou de querer erigir iniciativas desenvolvimentistas na comunidade, que não fluam de seu real estágio de cultura, condições e política de progresso coletivo. [...] o 'núcleo conceitual' do desenvolvimento local consiste no efetivo desabrochamento - a partir do rompimento de amarras que prendam as pessoas em seus status quo de vida - das capacidades, competências e habilidades de uma 'comunidade definida' (portanto com interesses comuns e situada em (...) espaço territorialmente delimitado, com identidade social e histórica), no sentido de ela mesma - mediante ativa colaboração de agentes externos e internos- incrementar a cultura da solidariedade em seu meio e se tornar paulatinamente apta a agenciar (discernindo e assumindo dentre rumos alternativos de reorientação do seu presente e de sua evolução para o futuro aqueles que se lhe apresentem mais consentâneos) e gerenciar (diagnosticar, tomar decisões, agir, avaliar, controlar, etc.) o aproveitamento dos potenciais próprios - ou cabedais de potencialidades peculiares à localidade, assim como a 'metabolização' comunitária de insumos e investimentos públicos e privados externos, visando à processual busca de soluções para os problemas, necessidades e aspirações, de toda ordem e natureza, que mais direta e cotidianamente lhe dizem respeito (ÁVILA, CAMPOS, et al. 2001).

A proposta de desenvolvimento local necessita, antes de tudo, ser movida pelo desejo de todos os 
agentes estarem envolvidos nessa busca autônoma do desenvolvimento de suas comunidades-localidades. Ávila (2000, p. 31-2) definiu que,

[...] a comunidade se configura por grupos de pessoas que se convergem, articulam e interagem através de relacionamentos primários e a sociedade também se constitui de grupo de pessoas que se convergem, articulam e interagem só que, ao inverso da comunidade, por relacionamentos secundários.

Conforme Ávila (2000) os relacionamentos primários baseiam-se em contatos e vínculos que se estabelecem no cotidiano das pessoas, de forma espontânea e informal, possibilitando o conhecimento, a avaliação e o controle do vivido nos territórios relacionais. Sua materialização se dá de forma dinâmica e construtiva nas vizinhanças, bairros, cidades e regiões que visam incentivar as iniciativas de Desenvolvimento Local, respeitando as peculiaridades das comunidades-localidades, bem como suas condições e potencialidades associativocooperativas. Já os relacionamentos secundários são gerados por normas, leis e regimentos que definem princípios jurídicos embasados no direito de que todos são iguais perante a lei, na perspectiva do coletivo.

\section{Considerações Finais}

O trabalho desenvolvido pelo Serviço Social na Comunidade Terapêutica Antônio Pio da Silva (COMTAPS), deixa clara a importância dessa atuação no tratamento a dependentes de substâncias psicoativas. O Serviço Social objetivando o resgate da cidadania dos residentes para reintegrá-los na sociedade, por meio de orientações e acompanhamento bem como aos seus familiares tem contribuído de modo significativo no tratamento dos internos.

Precisa-se antes de tudo não banalizar o termo reintegração social. Se hoje o usuário está na instituição para efeito de sua plena recuperação é em decorrência de vários problemas que acometeram sua vida particular e sua vida familiar e social. Identificar tais problemas e enfatizá-los ao longo do tratamento do usuário é de fundamental importância, para a recuperação dessa pessoa que de certa forma foi excluída ou se excluiu da sociedade, bem como teve seus laços familiares fragilizados, levando-a ao uso abusivo de substâncias psicoativas.

$\mathrm{Na}$ reinserção social devem ser levados em conta se quando a pessoa voltar ao convívio social se as condições estarão ou não diferentes daquelas que acarretaram o uso de substâncias psicoativas. Da mesma forma ainda restam dúvidas sobre recuperação da autonomia do usuário para conduzir sua vida de maneira digna e saudável.

Apesar do Serviço Social ser relativamente recente na Instituição notam-se os avanços em relação aos serviços oferecidos aos usuários e a articulação com as demais políticas públicas. Sempre é enfatizada a busca da autonomia dos internos, objetivando a reinserção na sociedade, para que o interno retome seus direitos e deveres como cidadão e tenha uma vida saudável em todos os sentidos. $\mathrm{O}$ assistente social atuante em uma comunidade terapêutica como modalidade de Organização não Governamental (ONG) deve lutar para que esta obtenha recursos próprios e atinja sua sustentabilidade. No âmbito do tratamento da dependência de substâncias psicoativas, o Serviço Social necessita articular com as esferas públicas e privadas visando à implementação de políticas públicas universalizantes que garantam a justiça social.

A atuação do profissional de serviço social no tratamento a dependente químico é complexa e exige o reconhecimento da doença do usuário, a desestruturação de seu contexto familiar e social e o trabalho em equipe visando sempre o atendimento como um todo.

\section{Referências}

ALVARENGA, S.; LUIS, M. (2004). A participação da família no processo de tratamento do alcoolista. Pesquisa sobre a prática da assistência a usuários de álcool e drogas no Estado de São Paulo: Editora Fundação Instituto de Enfermagem de Ribeirão Preto, p. 145.

ÁVILA, F. A; CAMPOS, I. M. M; ROSA, M. W. C.; FERRO, F. F. C.; PAULITISCH, R. J. (2001). Formação educacional em desenvolvimento local: relato de estudo em grupo e análise de conceitos. 2. ed. Campo Grande-MS: UCDB.

AVILA, V.F. ; COELHO, I.S. (2009). Performances comunitárias e vieses teóricos sobre potencialidades de participação no Jardim Sayonara - Campo Grande-MS - em ótica de Desenvolvimento Local. INTERAÇÕES.Campo Grande. vol.10 no.1 Campo Grande Jan./June.

ÁVILA, V.F. (1999). No município sempre a educação básica do Brasil. Campo Grande: UCDB.

BAUMAN, S. (2003).Comunidade: a busca por segurança. Trad. DENTIZIEN, P. Rio de Janeiro: Jorge Zahar.

COELHO, I. S.(2009). Performances comunitárias e vieses teóricos sobre potencialidades de participação no 117 Jardim Sayonara - Campo Grande-MS - em ótica de Desenvolvimento Local INTERAÇÕES, Campo Grande, v.10, n.1, p.97-117, jan./ jun.

DICIONÁRIO DE TERMOS técnicos da assistência social. (2007). Belo Horizonte: Ascom,

DOMINGOS, J. B. C. (2008). O uso de álcool e as condições de saúde entre motoristas nas estradas. Ribeirão Preto. p. 35, Tese (Mestrado) - Departamento de Enfermagem Psiquiátrica e Ciências Humanas da Escola de Enfermagem de Ribeirão Preto da Universidade de São Paulo.

DOWBOR, L. A intervenção dos governos locais no processo de desenvolvimento. In: BAVA, S. C. (org.)( 1996). Desenvolvimento local, geração de emprego e renda. São Paulo: Polis.

GALDURÓZ, J. C. F.(e col.). (2002). I Levantamento domiciliar sobre o uso de drogas no Brasil: estudo envolvendo as 107 maiores cidades do país: 2001. São Paulo, p. 07.

GOBIERNO BASCO. (1994). Estudios de economia, manual de desarrollo local. Vitoria-Gasteiz: Departamento de Economia y Hacienda,

LE BOURLEGAT, C. A. (2000). Ordem local como força interna de desenvolvimento. In: INTERAÇÕES .Revista Internacional de Desenvolvimento Local, v. 1, n. 1, p. 13-20, set..

LUÍS, M.; TAVEIRA, M.(2004.)A motivação inicial para a busca do tratamento da dependência química. Pesquisa sobre a prática da assistência a usuários de álcool e drogas no Estado de 
São Paulo: Editora Fundação Instituto de Enfermagem de Ribeirão Preto, p. 263.

MARQUES, H. R.. Desarrollo local a escala humana. Revista Polis. 22 Disponível em: http://www.revistapolis.cl/index.htm Acesso em 10.02.2011.

MARTÍN, J. C. (1999).Los retos por una sociedad a escala humana: el desarrollo local. In: SOUZA, M. A. Metrópole e gobalização: conhecendo a cidade de São Paulo. São Paulo: CEDESP,. p. 169-177.

MARTINS, S. R. O.( 2002). Desenvolvimento local: questões conceituais e metodológicas Local. INTERACÕES, Campo Grande, Vol. 3, N. 5, p. 51-59, Set.

MAX-NEEF, M.; ELIZALDE, A.; HOPENHAYN, M. (1986).Desarrollo a escala humana: una opción para el futuro. In: Development Dialogue (número especial). Santiago do Chile.

MOSCOVICI, F. (1999).Desenvolvimento interpessoal: treinamento em grupo. 6. ed. Rio de Janeiro: José Olympio,

PEREIRA, J.; PILLON, S. (2004). Alcoolismo e a Terapia Ocupacional. Pesquisa sobre a prática da assistência a usuários de álcool e drogas no Estado de São Paulo: Editora Fundação Instituto de Enfermagem de Ribeirão Preto

PIERSON, D. (1968).Teoria e pesquisa em sociologia. 11. ed. São Paulo: Melhoramentos.

SANTOS, A. (1996a).Natureza do espaço: técnica e tempo, razão e emoção. São Paulo: Hucitec.

SANTOS, M.. Espaço e método. São Paulo: Nobel, 1988.

TORRAS, M. (1995). La participación de los pueblos en su desarrollo. Barcelona: Intermón,.

Artigo produzido no contexto do Programa de Mestrado em Desenvolvimento Local da Universidade Católica Dom Bosco, na disciplina Desenvolvimento local: a dimensão humana e a solidariedade ativa no território.

Sobre os autores:

Celisa Aparecida Silva de Barros - Assistente social. Tutora externa da Uniasselvi, no curso de Serviço Social. Pos Graduada em Administração e Planejamento de Projetos Sociais Mestranda em Desenvolvimento Local/UCDB. Atuação na Comunidade Terapêutica Antônio Pio da Silva "Centro de Tratamento de Dependência Química Álcool e Drogas”, Campo Grande - MS. E-mail: celisa_beto@hotmail.com

Heitor Romero Marques - Licenciado em Ciências e Pedagogia [FUCMT], Especialista em Filosofia e História da Educação [FUCMT], Mestre em Educação: formação de professores [UCDB], Doutor em Desarrollo local y panteamiento territorial [COMPLUTENSE, Madrid]. Professor da Universidade Católica do Bom nos cursos de licenciatura e bacharelado, especialização lato sensu e no Programa de Mestrado em Desenvolvimento Local. E-mail: heiroma@ucdb.br; heiroma@ig.com.br 